\title{
Microstructure Development in Hot-Pressed Silicon Carbide: Effects of Aluminum, Boron, and Carbon Additives
}

Xiao Feng Zhang, Qing Yang, and Lutgard C. De Jonghe

Materials Sciences Division, Lawrence Berkeley National Laboratory, University of California, Berkeley, CA 94720, USA

Department of Materials Science and Mineral Engineering, University of California, Berkeley, CA 94720, USA

December 18, 2002

Submitted to

Acta Mater.

Work was supported by the Director, Office of Energy Research, Office of Basic Energy Sciences, Materials Sciences Division of the U.S. Department of Energy under Contract No. DE-AC03-76SF0098. 


\title{
Microstructure Development in Hot-Pressed Silicon Carbide: Effects of Aluminum, Boron, and Carbon Additives
}

\author{
Xiao Feng Zhang ${ }^{1}$, Qing Yang ${ }^{2}$, Lutgard C. De Jonghe ${ }^{1,2}$ \\ ${ }^{1}$ Materials Sciences Division, Lawrence Berkeley National Laboratory, University of \\ California, Berkeley, CA 94720 \\ ${ }^{2}$ Department of Materials Science and Mineral Engineering, University of California, \\ Berkeley, CA 94720
}

\begin{abstract}
:
$\mathrm{SiC}$ was hot-pressed with aluminum, boron, and carbon additives. The $\mathrm{Al}$ content was modified either to obtain $\mathrm{SiC}$ samples containing a continuous $\mathrm{Al}$ gradient, or to vary the average $\mathrm{Al}$ content. In both cases, dramatic changes in microstructure, phase composition, and grain boundary structure were observed as a result of the Al variation. Similar processing and characterization were done with modified boron and carbon average contents. The systematic experiments allowed identification of the roles of $\mathrm{Al}$, $\mathrm{B}$, and $\mathrm{C}$ in developing grain morphology and phase composition. The experiments also clarified the mechanical property responses to microstructural modification. Tailoring of the $\mathrm{SiC}$ microstructure to suit different applications would be possible.
\end{abstract}

Keywords: Silicon Carbides, Microstructure, Phase transformations, Grain boundary structure, TEM. 


\section{Introduction}

Silicon carbide is a desirable material for high temperature structural applications because of its light weight and outstanding high temperature mechanical properties (high hardness, high creep resistance, good chemical stability). However, the low fracture toughness of commercial $\mathrm{SiC}\left(3 \sim 5 \mathrm{MPa}^{1 / 2}\right)$ has detracted from its widespread applications. During the past decades, many efforts were made to improve the fracture toughness of SiC. In situ toughening was one of the promising approaches to improving the toughness of monolithic $\mathrm{SiC}$ [1-4]. A common feature of the in situ toughened $\mathrm{SiC}$ is a microstructure containing plate-like, elongated $\mathrm{SiC}$ grains with weak grain boundaries serving as preferred crack propagation paths $[1,5]$. R-curve toughening resulted from a combination of crack bridging, crack deflection, and grain pullout [6-9]. Becker et al. exploited similar toughening mechanisms in $\mathrm{Si}_{3} \mathrm{~N}_{4}[8,10]$.

Additions of aluminum metal or aluminum compounds as sintering additives have been known to facilitate liquid phase sintering of $\operatorname{SiC}[1,3,11-13]$, lower the densification temperature $[1,2,4,11,14-20]$, induce the phase transformations among $\mathrm{SiC}$ polytypes, promote anisotropic growth of $\mathrm{SiC}$ grains $[13,15,21]$, form amorphous grain boundary films, and produce various secondary phases in triple junction pockets [1, 5, 18, 22-26]. Cao et al. hot-pressed $\mathrm{SiC}$ in the presence of aluminum, boron, and carbon, (ABC-SiC), demonstrating excellent flexural strength, high fracture toughness, fatigue resistance, improved creep resistance, and enhanced wear resistance at ambient and elevated temperatures [18, 27-31]. Detailed transmission electron microscopy (TEM) study confirmed the existence of about $1 \mathrm{~nm}$ wide amorphous intergranular films (IGFs) [25], of which the Al-rich composition was quantitatively determined by nanoprobe electron-beam analysis [32]. Prolonged heating above $1000^{\circ} \mathrm{C}$ crystallized the amorphous IGFs [25]. Above $1300^{\circ} \mathrm{C}$, the $\mathrm{Al}$ concentration of the IGFs increased significantly as a result of $\mathrm{Al}$ rejection from the adjacent $\mathrm{SiC}$ grains [33-35]. These structural and chemical changes could be correlated with the substantive improvements of the high temperature mechanical properties of the ABC-SiC [27-30, 34, 36].

The effects of $\mathrm{Al}, \mathrm{B}$ and $\mathrm{C}$ on microstructural development have been further investigated. Two approaches were used for varying the $\mathrm{Al}$ content in the $\mathrm{SiC}$. In a first approach, an $\mathrm{Al}$ metal foil was embedded in $\mathrm{ABC}-\mathrm{SiC}$ powder mixtures and hot pressed. 
The second method changed the Al content systematically in a series of powder mixes. The first approach resulted in $\mathrm{SiC}$ with a continuous $\mathrm{Al}$ gradient, while the second method allowed for an accurate control of the additive contents. In the present paper, materials processing and characterization of these series of $\mathrm{SiC}$ samples prepared with various $\mathrm{Al}, \mathrm{B}$ and $\mathrm{C}$ contents are reported. The effects of the additives on the microstructural evolution are described and underlying mechanisms are proposed.

\section{Experimental}

\subsection{Materials processing}

Submicrometer $\beta$-SiC powders (BETARUNDUM, Grade ultra-fine, IBIDEN, Japan), with a mean particle size of $0.27 \mu \mathrm{m}$, were mixed with aluminum (H-3, Valimet, Stockton, CA), boron (Callery Chemical Co., Callery, PA), and carbon additives in toluene. The carbon was introduced as Apiezon wax (AVO Biddle Instruments, Blue Bell, PA), which was converted to carbon by pyrolysis. The standard recipe is $3 \mathrm{wt} \% \mathrm{Al}$,

$0.6 \mathrm{wt} \% \mathrm{~B}$, and $2 \mathrm{wt} \% \mathrm{C}$, with $94.4 \mathrm{wt} \% \beta$-SiC. In a series of samples, the $\mathrm{Al}$ content was increased by $1 \mathrm{wt} \%$ increments, at fixed boron and carbon contents. 3ABC-through 7ABC-SiC refer to such samples containing 3 to $7 \mathrm{wt} \% \mathrm{Al}$, respectively. The $3 \mathrm{ABC}-\mathrm{SiC}$ composition and treatment was similar to the $\mathrm{ABC}-\mathrm{SiC}$ reported before. In other samples, the boron or the carbon content was varied at fixed contents of the other additives (Al, C or Al, B, respectively).

The slurries were ultrasonically agitated, stir-dried, and sieved through a 200mesh screen. Green compacts were formed using uniaxial die pressing at $35 \mathrm{MPa}$, and hot pressed in a graphite die in two stages, first at $1500^{\circ} \mathrm{C}$ for 30 minutes, and second continued at $1900^{\circ} \mathrm{C}$, for 1 hour, at $50 \mathrm{MPa}$, under flowing argon. The final products were $38 \mathrm{~mm}$ diameter discs, $4 \mathrm{~mm}$ thick, and over $99 \%$ dense.

In another set of experiments, a pure Al metal foil was embedded in the sieved powder mixtures containing $\beta-\mathrm{SiC}, 0.6 \mathrm{wt} \%$ boron, and $2.0 \mathrm{wt} \%$ carbon. The subsequent die pressing and hot pressing were under the same conditions as described above. The 
embedded Al foil melted and spread through the surrounding powder, resulting in $\mathrm{SiC}$ discs with an $\mathrm{Al}$ gradient.

\subsection{Characterization}

X-ray diffraction (XRD) was used to quantify the volume fraction of SiC polytypes following the method proposed by Ruska et al. [37]. Room temperature fourpoint bending strength was measured on $3 \times 3 \times 30 \mathrm{~mm}$ beams with inner and outer spans of $9.5 \mathrm{~mm}$ and $25.4 \mathrm{~mm}$, respectively, at a cross-head speed of $0.05 \mathrm{~mm} / \mathrm{min}$. Hardness and fracture toughness were determined by Vickers indentation on polished samples, with a peak load of $98 \mathrm{~N}$.

Microstructural characterization was performed in a $200 \mathrm{kV}$ Philips CM200 transmission electron microscope. The Al concentration in the IGFs was analyzed by energy-dispersive X-ray spectroscopy (EDS), with a $10 \mathrm{~nm}$ diameter electron beam probe. The detailed methodology and experimental parameters for chemical analysis have been reported previously [32]. The polished $\mathrm{SiC}$ pieces were plasma-etched in $\mathrm{CF}_{4}$ containing $4 \% \mathrm{O}_{2}$, for scanning electron microscopy (SEM) examination.

\section{Results}

\subsection{Al-foil embedded $\mathrm{SiC}$}

A schematic cross-section and corresponding EDS analysis of the SiC processed with an embedded Al foil is shown in Fig. 1. A continuous Al gradient was found with

decreasing Al concentration away from the Al layer. The 3 wt $\%$ Al composition, corresponding to the usual ABC-SiC, was located at about $1250 \mu \mathrm{m}$ from the Al layer. 


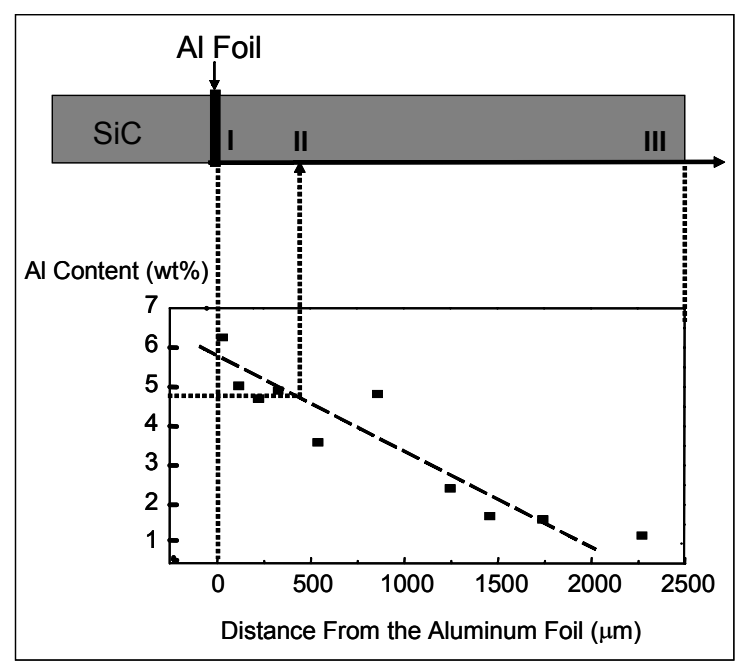

Fig. 1. Schematic illustration of $\mathrm{Al}$ gradient profile in $\mathrm{SiC}$ embedding an $\mathrm{Al}$ foil. The $3 \mathrm{wt} \% \mathrm{Al}$ concentration corresponding to the usual $\mathrm{ABC}-\mathrm{SiC}$, was located at about $1250 \mu \mathrm{m}$ from the $\mathrm{Al}$ layer. Spots marked by I, II, and III at Al contents of $\sim 6 \mathrm{wt} \%, \sim 5 \mathrm{wt} \%$, and $\sim 1 \mathrm{wt} \%$, respectively, correspond to the SEM micrographs shown in Fig. 2.

The microstructure was altered dramatically with changing Al content. SEM images at positions marked I, II, and III, in Fig. 1, with measured average Al contents of about $6 \mathrm{wt} \%, 5 \mathrm{wt} \%$, and $1 \mathrm{wt} \%$, respectively, are shown in Fig. 2. The microstructures consist of plate-like, elongated as well as equiaxed grains. Note the changes in area density, aspect ratio, and size uniformity of the elongated grains as a function of $\mathrm{Al}$ contents. The influence of $\mathrm{Al}$ on the aspect ratio of the $\mathrm{SiC}$ grains is particularly striking. Lower $\mathrm{Al}$ concentration corresponds to reduced aspect ratios, and eventually this ratio becomes almost unity at about $1 \mathrm{wt} \% \mathrm{Al}$, Fig. 2c. The correlation between microstructure and $\mathrm{Al}$ content shown in Fig. 2 cannot be regarded as quantitative here because of the local fluctuation in $\mathrm{Al}$ content, but the results do illustrate the general effect of $\mathrm{Al}$ content on the microstructure of $\mathrm{ABC}-\mathrm{SiC}$. 


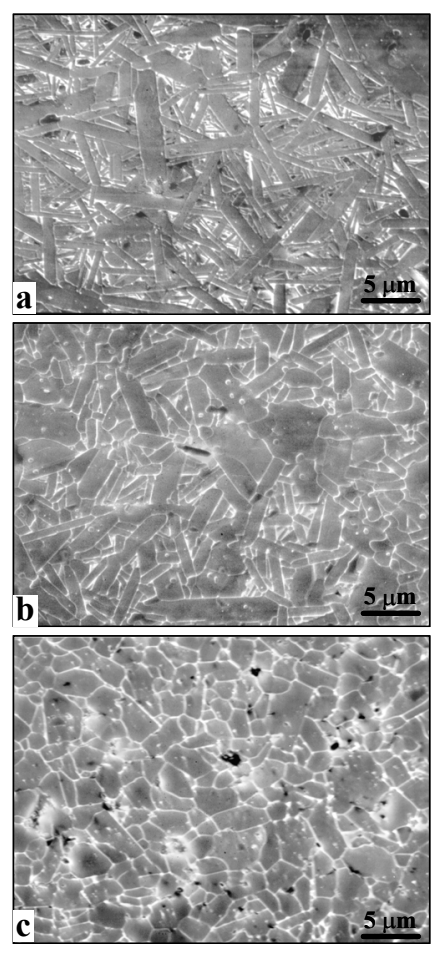

Fig. 2. SEM images from spots I, II, and III marked in Fig. 1. The corresponding Al contents are $\sim 6 \mathrm{wt} \%$, $\sim 5 \mathrm{wt} \%$, and $\sim 1 \mathrm{wt} \%$, respectively. Note the microstructural change as a function of Al content.

The microstructural changes caused by the Al variation affect significantly the mechanical properties of the ABC-SiC. For example, indentation toughness decreases with increasing $\mathrm{Al}$ as shown in Fig. 3. The large scatter in indentation toughness close to the $\mathrm{Al}$ foil is the result of persisting metallic aluminum. The change in indentation toughness further away from the foil corresponded to how cracks propagated in the $\mathrm{SiC}$. The SEM images in Fig. 4 showed tortuous intergranular cracks and grain bridging in areas I and II, and extensive transgranular cracking in area III marked in Fig. 1. The experiments using embedded $\mathrm{Al}$ in $\mathrm{SiC}$ indicate that it should be possible to alter microstructure and mechanical properties by adjusting the contents of sintering additives. To determine more precisely the roles of aluminum as well as boron and carbon on microstructural development, a series of $\mathrm{ABC}-\mathrm{SiC}$ samples were prepared and characterized. Each type of samples was processed changing only one of the additives at a time. 


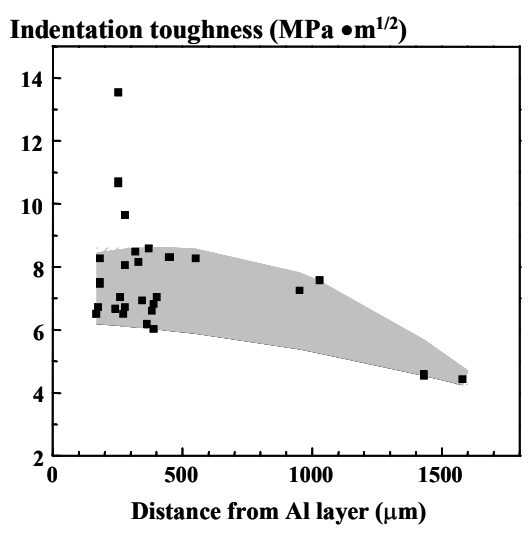

Fig. 3. Vickers indentation toughness obtained from various distances from the Al-layer in the Alembedded SiC.

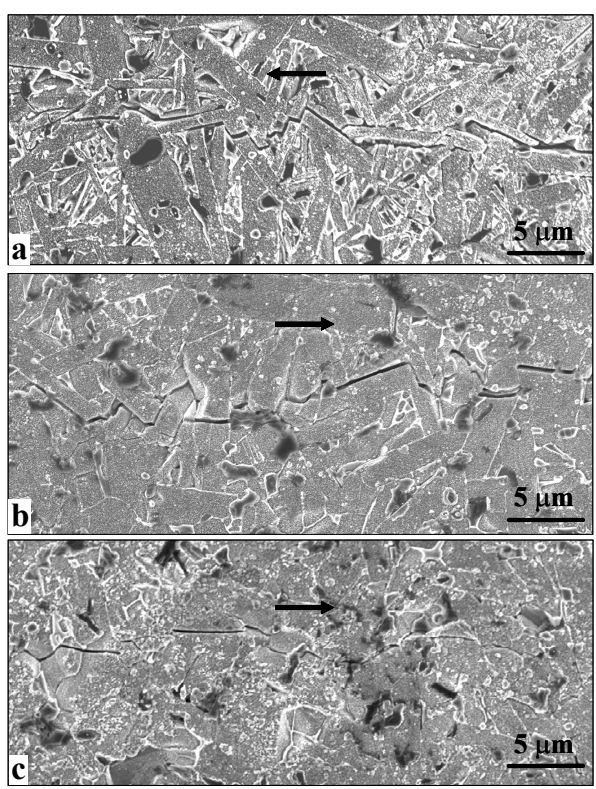

Fig. 4. SEM images showing intergranular cracks in (a) and (b), and transgranular crack in (c). (a), (b), and (c) were taken from spots I, II, and III in Fig. 1, corresponding to $6 \mathrm{wt} \%, 5 \mathrm{wt} \%$, and $1 \mathrm{wt} \% \mathrm{Al}$ concentration, respectively. The arrows indicate the directions of crack propagation.

\subsection{ABC-SiC with adjusted additive contents}

The nominal compositions of $3 \mathrm{ABC}$ - to $7 \mathrm{ABC}-\mathrm{SiC}$ samples at fixed boron and carbon content, and their densities after hot pressing are listed in Table 1. It can be seen that $\mathrm{Al}$ variation between 3 and $7 \mathrm{wt} \%$ did not reduce densification under the same 
processing conditions. Densities greater than $99 \%$ of theoretical were obtained for all samples. However, changing the Al content did alter the microstructure, as illustrated in Fig. 5a-e. Although all samples were composed of plate-like, elongated SiC grains and equiaxed $\mathrm{SiC}$ grains, the size, aspect ratio and area density of the elongated grains varied with increasing $\mathrm{Al}$ content. The plots in Fig. 5f present the change of length and aspect ratio of the elongated grains with $\mathrm{Al}$ content. The aspect ratio increases almost linearly up to $6 \mathrm{wt} \% \mathrm{Al}$, while the length of the elongated grains reaches a maximum at about 5 wt\% Al. The data for the grain morphologies are summarized in Table 1. Samples with more than $3 \mathrm{wt} \% \mathrm{Al}$ also exhibited a distinct bimodal grain distribution, in which the size of the equiaxed grains remains unchanged. It is worth noting that comparing to $3 \mathrm{ABC}$ $\mathrm{SiC}$, the aspect ratios in $4 \mathrm{ABC}-$ to $7 \mathrm{ABC}-\mathrm{SiC}$ are much higher, but the number density of the elongated grains continuously decreases.

Table 1. Nominal compositions, sample densities, and grain morphologies for a series of $\mathrm{ABC}-\mathrm{SiC}$ samples with increased Al content.

\begin{tabular}{|c|c|c|c|c|c|c|c|c|}
\hline \multirow{2}{*}{$\begin{array}{l}\text { Sample } \\
\text { Designation }\end{array}$} & \multirow{2}{*}{$\begin{array}{l}\mathrm{SiC} \\
(\mathrm{wt} \%)\end{array}$} & \multirow{2}{*}{$\begin{array}{l}\text { Al } \\
(\mathrm{wt} \%)\end{array}$} & \multirow{2}{*}{$\begin{array}{l}\text { Density } \\
\left(\mathrm{g} / \mathrm{cm}^{3}\right)\end{array}$} & \multicolumn{3}{|c|}{ Elongated Plate-like Grains } & \multirow{2}{*}{$\begin{array}{l}\text { Equiaxed } \\
\text { Grains } \\
\mathrm{d}(\mu \mathrm{m})\end{array}$} & \multirow{2}{*}{$\begin{array}{l}\text { Area Density } \\
\text { of Elongated } \\
\text { Grains }\left(\mathrm{mm}^{-2}\right)\end{array}$} \\
\hline & & & & $\begin{array}{l}\text { length } \\
l(\mu \mathrm{m})\end{array}$ & $\begin{array}{l}\text { width } \\
\mathrm{w}(\mu \mathrm{m})\end{array}$ & $\begin{array}{l}\text { aspect ratio } \\
l / \mathrm{w}\end{array}$ & & \\
\hline 3ABC-SiC & 94.4 & 3 & 3.18 & $4.4 \pm 1.4$ & $1.0 \pm 0.3$ & $4.7 \pm 1.6$ & - & 85,000 \\
\hline 4ABC-SiC & 93.4 & 4 & 3.24 & $11.7 \pm 8.0$ & $0.8 \pm 0.5$ & $14.9 \pm 6.0$ & $0.5 \pm 0.3$ & 57,000 \\
\hline 5ABC-SiC & 92.4 & 5 & 3.25 & $20.0 \pm 6.4$ & $0.8 \pm 0.3$ & $23.2 \pm 6.8$ & $0.6+0.2$ & 45,000 \\
\hline 6ABC-SiC & 91.4 & 6 & 3.13 & $9.1 \pm 3.0$ & $0.3 \pm 0.2$ & $30.8 \pm 10.6$ & $0.5 \pm 0.3$ & 25,000 \\
\hline 7ABC-SiC & 90.4 & 7 & 3.15 & $11.5+5.8$ & $0.4+0.2$ & $31.6+15.4$ & $0.6 \pm 0.3$ & 23,000 \\
\hline
\end{tabular}

All samples also contain $0.6 \mathrm{wt} \% \mathrm{~B}$ and $2 \mathrm{wt} \% \mathrm{C}$. 


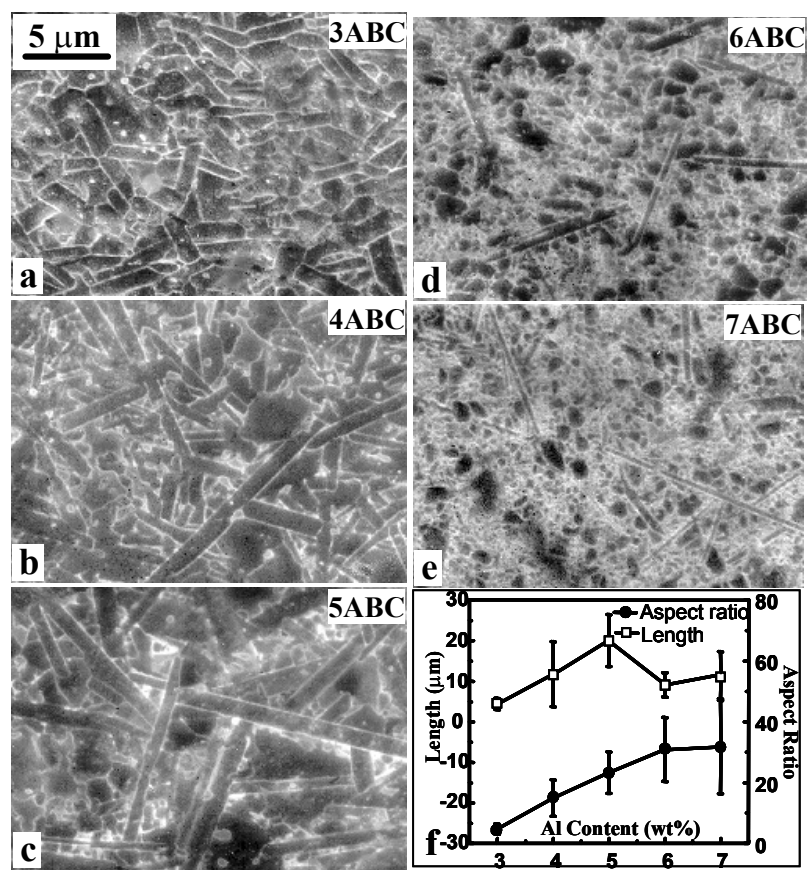

Fig. 5. Morphologies of 3ABC-, 4ABC-, 5ABC-, 6ABC-, and 7ABC-SiC are shown in images in (a) to (e). Changes in length and aspect ratio of the elongated grains with $\mathrm{Al}$ content are shown in (f).

Changing of the $\mathrm{Al}$ content by $1 \mathrm{wt} \%$ not only caused considerable change in grain morphology, but also induced different degrees of 3C-to-4H and/or $6 \mathrm{H}$-to-4H SiC phase conversion. XRD spectra were collected from polished surfaces of 3ABC- to 7ABC-SiC samples, and from the starting powder as well for a comparison. The spectra were matched with standard 3C-, 4H-, 6H-, and 15R-SiC phase spectra. The volume fraction of $\alpha-6 \mathrm{H}$ phase in the " $\beta-3 \mathrm{C} "$ starting powder was about $\sim 20 \%$. These submicron $6 \mathrm{H}$ seeds may grow into large $6 \mathrm{H}$ or $4 \mathrm{H}$ grains under suitable conditions. For the mainly $3 \mathrm{C}$ powders, extensive $\beta$-to- $\alpha$ phase transformation took place at processing temperature, as evident from others work on $\mathrm{SiC}$ involving $\mathrm{Al}$, $\mathrm{B}$ and $\mathrm{C}$ additives $[13,15,16,21,38]$. Our TEM examination showed that the equiaxed grains in $\mathrm{ABC}-\mathrm{SiC}$ samples were associated with non-transformed $\beta$-3C $\mathrm{SiC}$. The elongated grains corresponded to $\alpha$-phases, mainly $4 \mathrm{H}$ - and $6 \mathrm{H}-\mathrm{SiC}$, with minor $15 \mathrm{R}-\mathrm{SiC}$. In many $\alpha$-grains, $4 \mathrm{H} / 6 \mathrm{H}$ stacking faults were present.

The phase compositions determined by XRD are listed in Table 2. It can be seen that the $3 \mathrm{wt} \% \mathrm{Al}$ addition in $3 \mathrm{ABC}-\mathrm{SiC}$ was just to transform all of the preexisting $6 \mathrm{H}-$ 
phase into $4 \mathrm{H}-\mathrm{SiC}$, while more than $50 \%$ of the $\beta-3 \mathrm{C}$ transformed into $\alpha-4 \mathrm{H}$ phase as well. However, $1 \mathrm{wt} \%$ more in $\mathrm{Al}$ content (i.e. 4ABC-SiC) resulted in a completely different phase composition, in which the $\beta-3 \mathrm{C}$ phase became dominant and the fraction of $4 \mathrm{H}$ phase was reduced because of a retarded 3C-to-4H transformation. The volume fraction of $6 \mathrm{H}$ phase remained comparable with that in starting powder, indicating that a higher than $3 \mathrm{wt} \% \mathrm{Al}$ content did not further promote the $6 \mathrm{H}-\mathrm{to}-4 \mathrm{H}$ transformation. Further increases in $\mathrm{Al}$ monotonically decreased the degree of 3C-to-4H transformation (5ABC- through 7ABC-SiC in Table 2), and apparently inhibited the preexisting $6 \mathrm{H}$ phase to be transformed into $4 \mathrm{H}$. These results implied that the $3 \mathrm{C}$-to- $4 \mathrm{H}$ transformation was mainly promoted by boron and carbon (see later the effects of B and C), and the transformation was retarded when boron and carbon increases were compensated by increasing the $\mathrm{Al}$ content. The data in Table 1 and Table 2 also suggest close relationships between the phase composition and grain morphology, which would be expected if the $\beta$-to- $\alpha$ transformation promotes the grain elongation [39].

Table 2. XRD determined polytypic SiC phases and corresponding volume fractions in 3ABC- through 7ABC-SiC. Mechanical properties are also listed.

\begin{tabular}{|l|c|c|c|c|}
\hline $\begin{array}{c}\text { Sample } \\
\text { Designation }\end{array}$ & $\begin{array}{c}\text { Phase and Volume } \\
\text { Fraction }\end{array}$ & $\begin{array}{c}\text { 4-Point Bending } \\
\text { Strength (MPa) }\end{array}$ & $\begin{array}{c}\text { Toughness* } \\
\text { (MPa.m }{ }^{\mathbf{2}} \text { ) }\end{array}$ & $\begin{array}{c}\text { Hardness* } \\
\text { (GPa) }\end{array}$ \\
\hline $3 \mathrm{ABC}-\mathrm{SiC}$ & $\begin{array}{c}70 \% 4 \mathrm{H} \\
30 \% 3 \mathrm{C}\end{array}$ & $691 \pm 12$ & $5.6 \pm 0.3$ & 24.1 \\
\hline $4 \mathrm{ABC}-\mathrm{SiC}$ & $19 \% 6 \mathrm{H}, 23 \% 4 \mathrm{H}$ & $561 \pm 13$ & $6.3 \pm 0.7$ & 23.9 \\
\hline $5 \mathrm{ABC}-\mathrm{SiC}$ & $21 \% 6 \mathrm{H}, 11 \% 4 \mathrm{H}$ & $480 \pm 30$ & $5.2 \pm 0.4$ & 22.7 \\
\hline $6 \mathrm{ABC}-\mathrm{SiC}$ & $24 \% 6 \mathrm{H}$ & & $3.2 \pm 0.2$ & 35.9 \\
\hline $7 \mathrm{ABC}-\mathrm{SiC}$ & $20 \% 6 \mathrm{C}$ & $598 \pm 34$ & & 30.1 \\
\hline
\end{tabular}

$*$ Vickers indentation, Load $=10 \mathrm{~kg} . \mathrm{E}=430 \mathrm{GPa}$ for the calculation. 
The changes in microstructure can be expected to affect mechanical properties. Table 2 lists various mechanical properties for the sample series. Indeed, the values for bending strength, toughness, and hardness differed for different samples. While the highest strength was obtained in $3 \mathrm{ABC}-\mathrm{SiC}$, the hardness was the maximum for $6 \mathrm{ABC}$ SiC. As for toughness, although the Vickers indentation test (in contrast to R-curve testing) does not give quantitative value for the polycrystalline ceramics with grain size much smaller than indentor, the data may be used for rough comparison. It is clear that 6 $\mathrm{wt} \%$ or higher $\mathrm{Al}$ additions degraded the toughness. Below $6 \mathrm{wt} \% \mathrm{Al}$, toughness values look comparable. The mechanical data in Table 2 illustrate that property tradeoff is often encountered in developing ceramic materials.

In addition to the grain morphology, a factor that may have a determining influence on mechanical properties of dense, polycrystalline ceramic materials is the grain boundary structure and composition. High-resolution electron microscopy was used to study individual IGFs, and EDS analysis quantified Al concentrations both in the $\mathrm{SiC}$ matrix grains and in the IGFs. Fig. 6 shows high-resolution micrographs obtained from 4ABC-, 5ABC-, and 7ABC-SiC, respectively. Similar to 3ABC-SiC [25], and to other SiC samples studied by other groups [5, 22, 23], amorphous IGFs were observed in 4ABC-SiC. However, in contrast to the finding that more than $85 \%$ of the examined IGFs were amorphous in $3 \mathrm{ABC}-\mathrm{SiC}$, the fraction of the amorphous IGFs in $4 \mathrm{ABC}-\mathrm{SiC}$ was only about $40 \%$, while the remaining $60 \%$ of the IGFs were crystalline. In $5 \mathrm{ABC}$ $\mathrm{SiC}$, about $50 \%$ IGFs examined were amorphous, while the remaining $50 \%$ of the IGFs were crystalline. Crystalline IGFs were prevalent in 6ABC- and 7ABC-SiC. Statistical measurements for the chemical widths of the IGFs are listed in Table 3. All of the IGFs, regardless of their structure, have a width of about 0.8 to $1 \mathrm{~nm}$. Table 3 also lists Al site densities in grain boundaries $\left(\mathrm{N}_{\mathrm{Al}}^{\mathrm{GB}}\right)$ and in $\mathrm{SiC}$ matrix grains $\left(\mathrm{N}_{\mathrm{Al}}{ }^{\mathrm{G}}\right)$. It can be seen that increasing the overall $\mathrm{Al}$ content enhanced $\mathrm{Al}$ concentration in the IGFs, as well as in the $\mathrm{SiC}$ grains bulk, but these concentrations saturated in the 5ABC-SiC. More than $5 \mathrm{wt} \%$ $\mathrm{Al}$ resulted in precipitation of excessive free $\mathrm{Al}$, as observed in $6 \mathrm{ABC}$-and $7 \mathrm{ABC}-\mathrm{SiC}$. 


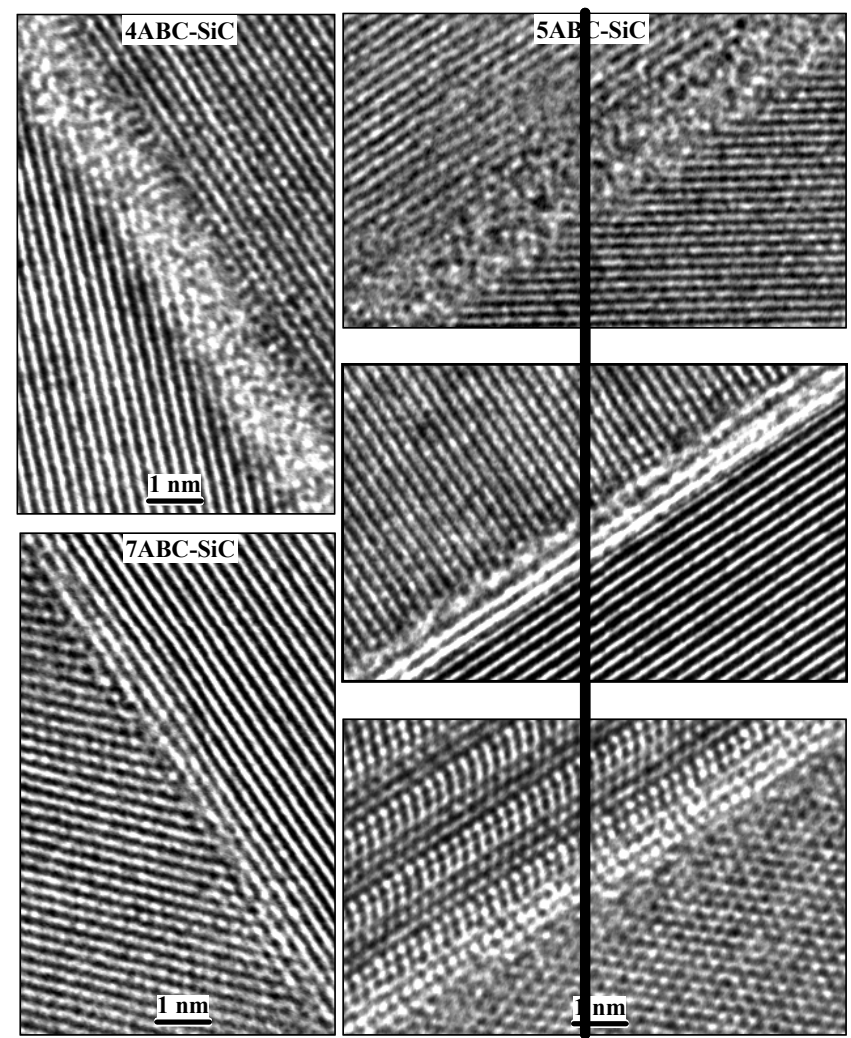

Fig. 6. High-resolution electron micrographs showing amorphous IGF structure in 4ABC-, and crystalline IGF structure in 7ABC-SiC. Both amorphous and crystalline IGFs were present in 5ABC-SiC.

Table 3. Summarized information for the IGFs in 3ABC-, 5ABC-, and 7ABC-SiC. IGF widths were determined from high-resolution electron microscopic images. $\mathrm{N}_{\mathrm{Al}}^{\mathrm{GB}}$ and $\mathrm{N}_{\mathrm{Al}}{ }^{\mathrm{G}}$ denote $\mathrm{Al}$ site densities in grain boundaries and in $\mathrm{SiC}$ matrix grains, respectively. The values were determined using quantitative EDS analysis. Standard deviations were adopted for all values.

\begin{tabular}{|c|c|c|c|c|}
\hline Samples & $\begin{array}{c}\text { Prevalent IGF } \\
\text { Structure }\end{array}$ & $\begin{array}{c}\text { IGF Width } \\
\mathbf{( n m )}\end{array}$ & $\mathbf{N}_{\mathbf{A l}}{ }^{\mathbf{G B}} \mathbf{( \mathbf { n m } ^ { - 3 } )}$ & $\left.\mathbf{N}_{\mathbf{A l}}{ }^{\mathbf{G}} \mathbf{( n m}^{\mathbf{- 3}}\right)$ \\
\hline 3ABC-SiC & Amorphous & $0.88 \pm 0.16$ & $15.6 \pm 2.7$ & $0.28 \pm 0.03$ \\
\hline 5ABC-SiC & $\begin{array}{c}\text { Amorphous \& } \\
\text { Crystalline }\end{array}$ & $0.85 \pm 0.21$ & $20.6 \pm 5.3$ & $0.41 \pm 0.06$ \\
\hline 7ABC-SiC & Crystalline & $0.76 \pm 0.22$ & $19.6 \pm 6.6$ & $0.41 \pm 0.07$ \\
\hline
\end{tabular}


In a previous study, it was demonstrated that amorphous IGFs in ABC-SiC $(3 \mathrm{ABC})$ can be fully crystallized through post-annealing, and one of the crystalline structures in agreement with high-resolution images and quantitative EDS analysis was a $2 \mathrm{H}$-wurtzite aluminosilicate [25]. In the present paper, crystalline IGFs in 5ABC-, $6 \mathrm{ABC}-, 7 \mathrm{ABC}-\mathrm{SiC}$ were prevalently formed in as-hot-pressed $\mathrm{SiC}$ without any posttreatment, but the same aluminosilicate structure was determined on the basis of highresolution imaging and EDS analysis. It is thus plausible that enhanced Al in IGFs facilitates formation of crystalline Al-Si-O-C IGFs.

Similar to the aluminum concentration variations, we also adjusted the boron and carbon contents. Typical results are shown in Fig. 7. In this case, the Al content was fixed at $6 \mathrm{wt} \%$, while either the $\mathrm{B}$ or the $\mathrm{C}$ concentrations was changed. The phase composition determined by XRD is noted in each SEM image. It is clear that at fixed $\mathrm{Al}$ $(6 \mathrm{wt} \%)$ and $\mathrm{B}(0.6 \mathrm{wt} \%)$ contents, $1 \mathrm{wt} \%$ additional carbon promoted formation of more elongated grains and enhanced the 3C-to- $4 \mathrm{H}$ transformation (most of the $6 \mathrm{H}$ phase should originate from starting powder). This effect of carbon on 3C-to-4H transformation was also reported before by Sakai et al [38]. Growth of the equiaxed grains was limited. When $\mathrm{Al}$ and $\mathrm{C}$ contents were kept constant, increasing boron content from $0.6 \mathrm{wt} \%$ to $0.9 \mathrm{wt} \%$ largely increased the number density of the elongated grains, with a coarsened volume but reduced aspect ratio. In addition, boron promoted the $3 \mathrm{C}$-to- $4 \mathrm{H}$ and $6 \mathrm{H}$-to$4 \mathrm{H}$ phase transformations, more effectively than carbon. The positive effect of boron on $6 \mathrm{H}$-to-4H transformation agreed with observations of Huang et al [16]. 


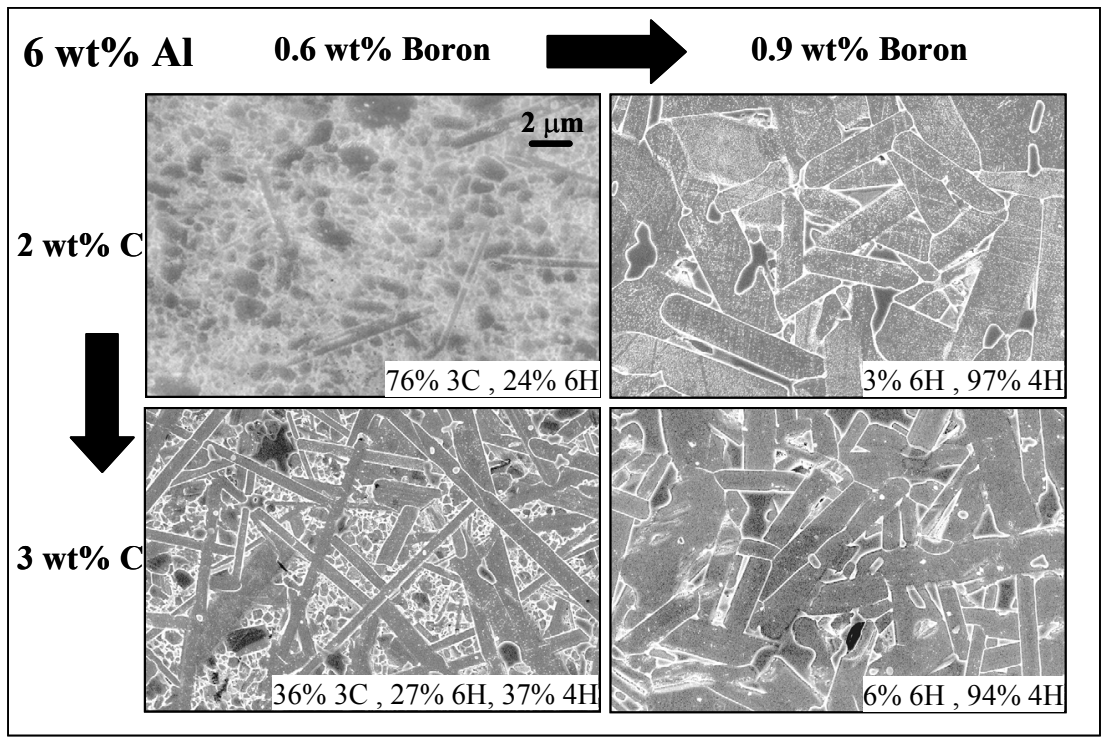

Fig. 7. Microstructural changes with adjusted boron or carbon content. Phase compositions are marked in each image. Effects of boron and carbon additions are obvious. Note the bimodal grain systems with 0.6 $\mathrm{wt} \%$ boron, and elongated monomodal grain systems with $0.9 \mathrm{wt} \%$ boron.

The systematic processing and characterizations of a series of $\mathrm{ABC}-\mathrm{SiC}$ described above, allowed a determination of the roles of $\mathrm{Al}, \mathrm{B}$, and $\mathrm{C}$ additives in developing the microstructures of silicon carbides. The observed effects may be summarized as follows: In terms of developing phase composition, boron is more effective in promoting the $\beta$-to$\alpha$ phase transformations than carbon. Aluminum retards the $\beta$-to- $\alpha$ phase transformations, but promotes $6 \mathrm{H}-$ to $-4 \mathrm{H}$ transformation. As for the developing grain morphology, aluminum and carbon promote anisotropic grain growth, whereas boron tends to coarsen the volume but reduce the aspect ratio of the elongated grains.

It should be noted that during materials processing, the combined roles often override individual roles of $\mathrm{Al}, \mathrm{B}$ and $\mathrm{C}$ additives. For example, both boron and carbon together favor of the $\beta$-to- $\alpha$ phase transformations associated with grain elongation [39]. However, the final microstructure does not necessarily lead to strongly elongated grains as boron and carbon additives have opposite effects on anisotropic grain growth. The $\mathrm{B} / \mathrm{C}$ ratio determines the final grain configuration. Aluminum has a different effect: when the $\mathrm{B} / \mathrm{C}$ ratio favors the anisotropic grain growth, $\mathrm{Al}$ accelerates such growth so that the aspect ratio is further increased. However, if $\mathrm{Al} / \mathrm{B}$ and $\mathrm{Al} / \mathrm{C}$ ratios are reduced, 
less liquid phases are expected to be present after Al-B-C reactions so that the effects of $\mathrm{Al}$ are diminished (Fig. 2). Further experiments indicated that even at constant Al/B/C ratios, change in total amount additives could still alter grain configuration and phase composition significantly. This emphasizes that both ratios and total amounts of sintering additives need to be considered in pursuing the desired materials.

Combining the results in Table 2, Fig. 5 and Fig. 6, it can be demonstrated that the microstructure indeed correlates to the mechanical performance. By examining the cracking mode in ceramic materials, the response of many mechanical properties to structural modification can be understood. Fig. 8 shows how cracking mode changes in 3ABC- to 7ABC-SiC samples. The crack profiles in Fig. 8a and Fig. 8b show tortuous intergranular paths in $3 \mathrm{ABC}-$, and $4 \mathrm{ABC}-\mathrm{SiC}$, respectively, as a result of amorphous grain boundary structure. Bridging and pullout of individual elongated grains can be seen on the cracking wakes. The deflected crack penetration, grain bridging, and pullout are the fundamental factors in in-situ toughening mechanism for the ABC-SiC [9, 36]. Similar intergranular cracking can be seen in 5ABC-SiC, Fig. 8c, but the bridging is by a group of grains rather than by individual grains. The cracks in 6ABC- and 7ABC-SiC are straight and transgranular (Fig. 8d, Fig. 8e), showing no grain bridging and pullout, as a consequence of the low volume fraction of elongated grains and strong crystalline bonding at grain boundaries as in commercial Hexoloy SiC [9]. Fracture toughness declined dramatically in 6ABC- and 7ABC-SiC. 

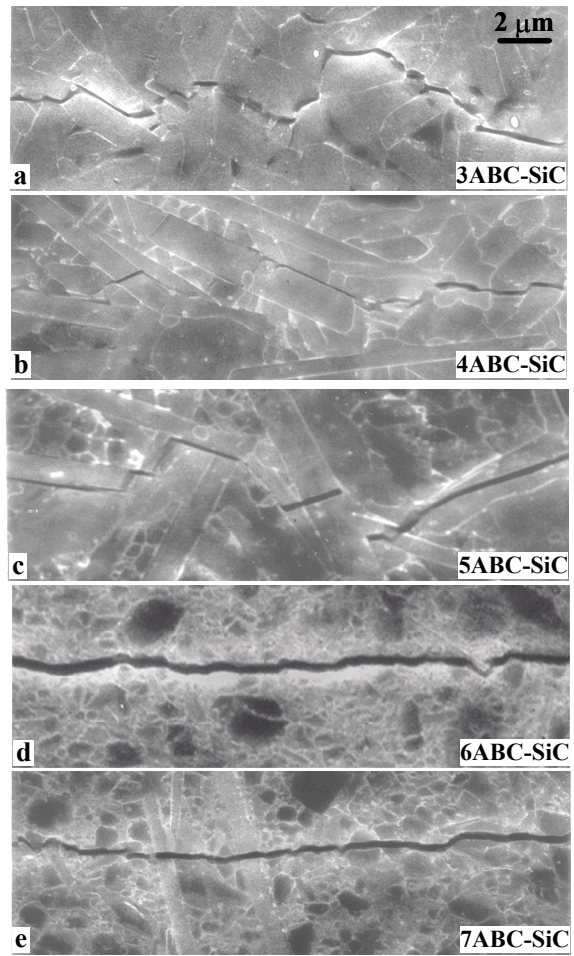

Fig. 8. Crack profiles in hot-pressed 3ABC- through 7ABC-SiC. The cracking modes can be directly correlated with the structural modification induced by increasing $\mathrm{Al}$ in starting powder mixtures.

\section{Discussion}

\subsection{Mechanism for phase transformation and effects of additives}

Cubic $3 \mathrm{C}-\mathrm{SiC}$ is metastable in comparison with hexagonal $15 \mathrm{R}$ - and $6 \mathrm{H}-\mathrm{SiC}$ phases $[15,40]$, causing the $\beta$-to- $\alpha$ phase transformations at high temperature. Pezoldt further clarified the transformation mechanism through study of boron diffusion in $3 \mathrm{C}$ $\mathrm{SiC}$ [41]. He concluded that above $1800{ }^{\circ} \mathrm{C}$, the $3 \mathrm{C}$-to- $15 \mathrm{R}$ and $3 \mathrm{C}$-to- $6 \mathrm{H}$ transformations took place through a mechanism in which atomic layer displacements changed the stacking sequence, transforming one $\mathrm{SiC}$ polytype into another [41]. This mechanism agrees with observations published in a series of papers in 1978 and 1981. In these papers, convincing TEM evidence was presented for the mechanisms of $\beta$-to- $\alpha$ phase transformations in $\mathrm{SiC}$ sintered with boron and carbon [42-45]. The same layerdisplacement mechanism should operate in the ABC-SiC studied here. Fig. 9 shows a high-resolution electron micrograph taken from a $\mathrm{SiC}$ grain in $3 \mathrm{ABC}-\mathrm{SiC}$. The $3 \mathrm{C}$-to- $4 \mathrm{H}$ transformation associated with the layer displacement in the $\{111\}$ plane of the cubic $3 \mathrm{C}$ 
structure is clearly seen. A super-ledge at the front of a $4 \mathrm{H}$ zone can be seen which is growing into the $3 \mathrm{C}-\mathrm{SiC}$ grain. Strain contrast is observed at the $4 \mathrm{H} / 3 \mathrm{C}$ ledge interface, where sintering additives may possibly concentrate, facilitating the transformation. Additional TEM studies of the $\beta$-to- $\alpha$ transformation in silicon carbide were done by

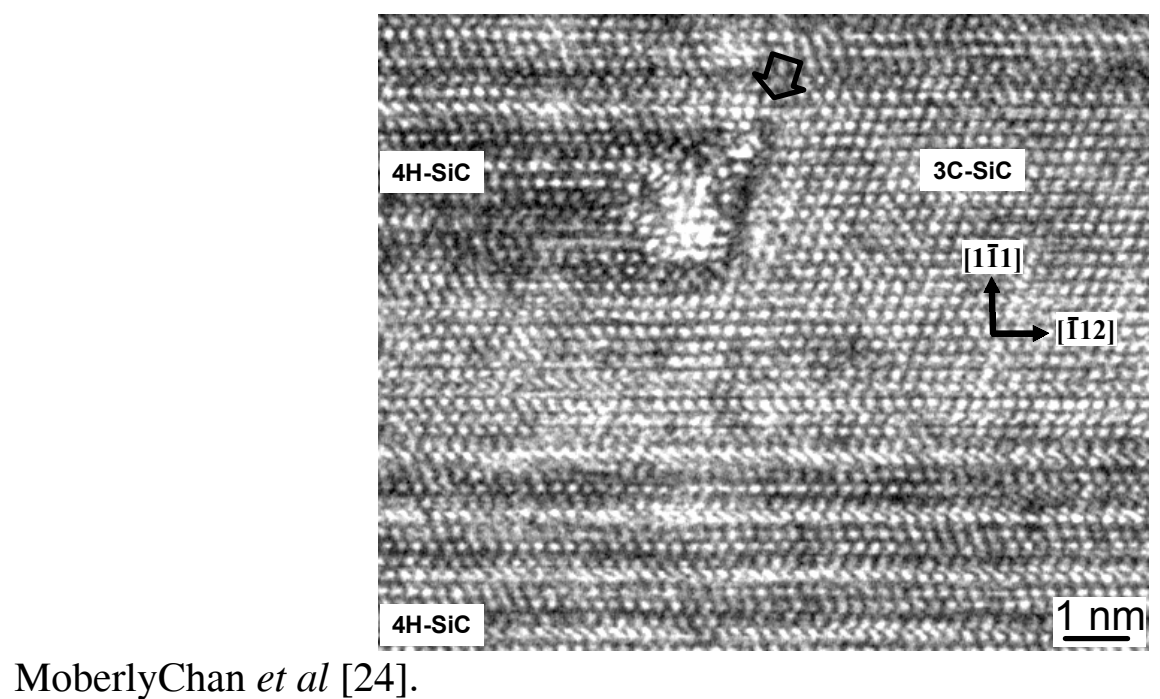

Fig. 9. High-resolution electron microscopic image taken from a SiC grain in 3ABC-SiC. The electron beam is parallel to the [110] zone axis direction of 3C-SiC phase. Polytype 4H/3C/4H layers can be seen with habit planes parallel to the (1) $\overline{1} 1)$ planes of the cubic $3 \mathrm{C}-\mathrm{SiC}$ and the (0001) planes of hexagonal $4 \mathrm{H}-$ $\mathrm{SiC}$. An arrow indicates a ledge at the front of a $4 \mathrm{H}$ zone.

In the layer-displacement mechanism, boron promotes the $\beta$-to- $\alpha$ phase transformations mainly through diffusion in SiC lattice. Studies by Zhang et al. confirmed boron presence in the $\mathrm{SiC}$ lattice [35], but not in the intergranular films [25]. Instead, the excess boron reacted with $\mathrm{Al}$ and $\mathrm{C}$ to form $\mathrm{Al}-\mathrm{B}-\mathrm{C}$ secondary phase particles [26]. This observation supports the work of Pezoldt [41], and conclusion that dissolved boron within $\mathrm{SiC}$ grains adds to the driving force for the $\beta$-to- $\alpha$ transformations in $\mathrm{ABC}-\mathrm{SiC}$. Carbon additions can strengthen the boron effect by preventing the reaction between boron and $\mathrm{SiO}_{2}$ oxidation layers. In addition, Rijswijk et al. reported that carbon reduces the loss of boron in the $\mathrm{SiC}$ lattice [46]. Therefore, the boron and carbon appear to have similar promotional effects on the $\beta$-to- $\alpha$ phase transformations as observed in 
the present study as well as discussed in other publications [46, 47], but the effect of boron is more pronounced. It can be concluded that boron and carbon are key elements in inducing $\beta$-to- $\alpha$ phase transformations in $\mathrm{SiC}$. This explains why a dominant volume fraction of $\alpha$-phases is produced when sintering $\beta$-SiC powder with boron and carbon additives only, without Al $[42,47]$. Aluminum additions, however, will react with boron and carbon at elevated temperatures to form secondary phases, thereby indirectly weakening the effect of boron and carbon on the $\beta$-to- $\alpha$ phase transformations.

\subsection{Mechanism for $A l, B$ and $C$ effects on grain morphology development}

Both boron and carbon have been found to increase bulk diffusion of SiC. Carbon additions increase the overall self-diffusion rate of $\mathrm{SiC}$ by a factor of 100 according to Rijswijk et al [46]. A similar effect was found for boron by Friedrich et al. [48]. Boron and carbon also enhance grain boundary diffusion. Prochazka et al. first proposed that boron and carbon could produce a driving force for diffusional mass transport necessary for sintering, by reducing the grain boundary energy [47]. This assumption was confirmed by other groups in the following years. It has been recognized that at $1200-1600{ }^{\circ} \mathrm{C}$, boron and carbon react with $\mathrm{SiO}_{2}$ surface layers on $\mathrm{SiC}$ powders, reducing the grain boundary energy, and in turn increasing grain boundary diffusion [2, $46,49,50]$. This reaction could also prevent reaction between $\mathrm{SiC}$ and the surface $\mathrm{SiO}_{2}$ at sintering temperature $[50,51]$. The effects of boron and carbon on increasing bulk and grain boundary diffusion rates allow densification of $\mathrm{SiC}$ and lead to a variety of grain morphologies, as discussed e.g. by Heuer et al. [e.g. 42]). However, boron and carbon only incorporate in $\mathrm{SiC}$ lattice, and by themselves do not form intergranular films. Temperatures in excess of $2000^{\circ} \mathrm{C}$ are often required to densify $\mathrm{SiC}$ when boron and carbon are the only additives.

It has been well recognized that the most important role of $\mathrm{Al}$ as an additive is to lower the densification temperature through formation of liquid and vapor phases that spread and wet SiC grains. The intergranular liquid films provide much faster mass transport paths than in solid-phase sintering, so that grain boundary dissolutionreprecipitation can become the dominant sintering mechanism. The nucleation and 
growth of $\alpha$-phases from $3 \mathrm{C}$-SiC starting powder can thus be significantly affected by the presence of the Al-based intergranular films, surpassing the effects of $t$ boron and carbon in controlling anisotropic grain growth (see Fig. 5 and 7). Increasing the $\mathrm{Al} / \mathrm{B}$ and $\mathrm{Al} / \mathrm{C}$ ratios, as in $3 \mathrm{ABC}$ - to $7 \mathrm{ABC}-\mathrm{SiC}$, results in boron and carbon depletion by dissolution into the liquid phases. The change of liquid compositions certainly affected the chemical environment, the stability, and the viscosity of the liquid phases surrounding $\mathrm{SiC}$ grains. For example, for the Al-O-Si-C liquid formed in $\mathrm{ABC}-\mathrm{SiC}$ [25], thermodynamic analysis indicated that adequate free carbon would stabilize the liquid phase at high temperature [12], the persistent liquid phase then benefits the grain elongation.

\section{Concluding Remarks}

A series of $\mathrm{ABC}-\mathrm{SiC}$ samples were prepared by hot pressing with varying contents of $\mathrm{Al}, \mathrm{B}$ and $\mathrm{C}$. Changes resulted in grain morphology, phase composition, grain boundary structure, and mechanical properties. Systematic characterizations showed that boron and carbon additions were effective in promoting the $\beta$-to- $\alpha \mathrm{SiC}$ polytypic phase transformations via bulk diffusion in $3 \mathrm{C}$-grains. Al additives enhanced $6 \mathrm{H}$-to- $4 \mathrm{H}$ transformation, but had limited effect on the $\beta$-to- $\alpha$ transformations. $\mathrm{Al}$ additions played a determining role in developing elongated $\mathrm{SiC}$ grains that are important for in situ toughening SiC.

The combined effects of $\mathrm{Al}, \mathrm{B}$, and $\mathrm{C}$ should be taken into account in controlling microstructure. Increasing $\mathrm{Al}$ reduces the number density but increases the aspect ratio of the elongated $\mathrm{SiC}$ grains. Changing carbon or boron contents changes the driving forces for the phase transformation. At the same time, the viscosity and chemistry of the Al-based grain boundary liquid were also changed. The identification of the roles and mechanisms of $\mathrm{Al}, \mathrm{B}$, and $\mathrm{C}$ additives in sintering $\mathrm{SiC}$ with adjustable microstructures allows a path to optimizing the desired mechanical properties of $\mathrm{ABC}-\mathrm{SiC}$.

\section{Acknowledgment:}

This work was supported by the Director, Office of Energy Research, Office of Basic Energy Sciences, Materials Sciences Division of the U.S. Department of Energy 
under Contract No. DE-AC03-76SF0098. Part of this work was made possible through the use of the National Center for Electron Microscopy facility at the Lawrence Berkeley National Laboratory. 


\section{REFERENCES}

1. Lange, F.F., J. Mater. Sci., 1975, 10, 314.

2. Tanaka, H., Inomata, Y., Hara, K. and Hasegawa, H., J. Mater. Sci. Lett., 1985, 4, 315.

3. Lin, B.W., Imai, M., Yano, T. and. Iseki, T, J. Am. Ceram. Soc., 1986, 69, C-67.

4. Padture, N.P., J. Am. Ceram. Soc., 1994, 77, 519.

5. MoberlyChan, W.J., Cao, J.J. and De Jonghe, L.C., Acta Mater., 1998, 46, 1625.

6. Faber, K.T. and Evans, A.G., Acta Metall., 1983, 31, 565.

7. Faber, K.T. and Evans, A.G., Acta Metall., 1983, 31, 577.

8. Becher, P.F., J. Am. Ceram. Soc., 1991, 74, 255.

9. Gilbert, C.J., Cao, J.J., De Jonghe, L.C. and Ritchie, R.O., J. Am. Ceram. Soc., 1997, 80, 2253.

10. Becher, P.F., Sun, E.Y., Plucknett, K.P., Alexander, K.B., Husueh, C.-H., Lin, H.T., Waters, S.B. and Westmoreland, C.G., J. Am. Ceram. Soc., 1998, 81, 2821.

11. Alliegro, R.A., Coffin, L.B. and Tinklepaugh, J.R., J. Am. Ceram. Soc., 1956, 39, 386.

12. Misra, A.K., J. Am. Ceram. Soc., 1991. 74, 45.

13. Zhou, Y., Tanaka, H., Otani, S. and Bando, Y., J. Am. Ceram. Soc., 1999, 82, 1959.

14. Omori, M. and Takei, H., J. Am. Ceram. Soc., 1982, 65, C-923.

15. Williams, R.M, Juterbock, B.N., Shinozaki, S.S., Peters, C.R. and Whalen, T.J., Am. Ceram. Soc. Bull., 1985, 64, 1385.

16. Huang, J.-L., Hurford, A.C., Cutler, R.A. and Virkar, A.V., J. Mater. Sci. Lett., 1986, 21, 1448.

17. Mulla, M.A. and Krstic, V.D., Am. Ceram. Bull., 1991, 70, 439.

18. Cao, J.J., MoberlyChan, W.J., De Jonghe, L.C., Gilbert, C.J. and. Ritchie, R.O, J. Am. Ceram. Soc., 1996, 79, 461.

19. Tanaka, H. and Zhou, Y., J. Mater. Res. 1999, 4, 518.

20. Nagano, T., Kaneko, K., Zhan, G.-D. and Mitomo, M., J. Am. Ceram. Soc., 2000, 83, 2781. 
21. Tanaka, H., Yoshimura, H.N., Otani, S., Zhou, Y. and Toriyama, M., J. Am. Ceram. Soc., 2000, 83, 226.

22. Hamminger, R., Grathwohl, G. and Thummler, F., J. Mater. Sci., 1983, 18, 353.

23. Sigl, L. and Kleebe, H.-J., J. Am. Ceram. Soc., 1993, 76, 773.

24. MoberlyChan, W.J. and De Jonghe, L.C., Acta Mater., 1998, 46, 2471.

25. Zhang X.F., Sixta, M.E. and De Jonghe, L.C., J. Am. Ceram. Soc., 2000, 83, 2813.

26. Zhang, X.F., Sixta, M.E. and De Jonghe, L.C, J. Am. Ceram. Soc., 2001, 84, 813.

27. Chen, D., Gilbert, C.J., Zhang, X.F. and Ritchie, R.O., Acta Mater., 2000, 48, 659.

28. Chen, D., Zhang, X.F. and Ritchie, R.O., J. Am. Ceram. Soc., 2000, 83, 2079.

29. Chen, D., Sixta, M.E., Zhang, X.F., De Jonghe, L.C. and Ritchie, R.O., Acta Mater., 2000, 48, 4599.

30. Sixta, M.E., Zhang, X.F. and De Jonghe, L.C., J. Am. Ceram. Soc., 2001, 84, 2022.

31. Zhang, X.F., Lee, G.Y., Chen, D., Ritchie, R.O. and De Jonghe, L.C., J. Am. Ceram. Soc., in review.

32. Zhang, X.F., Yang, Q., De Jonghe, L.C. and Zhang, Z., J. Microsc., 2002, 207, 58.

33. Zhang, X.F. and De Jonghe, L.C., to be submitted.

34. Zhang, X.F., Sixta, M.E. and De Jonghe, L.C., Defect and Diffusion Forum, 2000, 186-187, 45.

35. Zhang, X.F., Sixta, M.E. and De Jonghe, L.C., J. Am. Ceram. Soc. J. Mater. Sci., 2001, 36, 5447.

36. Ritchie, R.O., Chen, D. and Zhang, X.F., Int. J. Mater. Prod. Tech., (2001, 1,331.

37. Ruska, J., Gauckler, L.J., Lorenz, J. and Rexer, H.U., J. Mater. Sci., 1979, 14, 2013.

38. Sakai, T. and Aikawa, T., J. Am. Ceram. Soc., 1988, 71, C-7.

39. MoberlyChan, W.J., Cao, J.J., Gilbert, C.J., Ritchie, R.O. and De Jonghe, L.C., The Cubic-to-Hexagonal Transformation to Toughen SiC. In: Tomsia A.P. and Glaeser A. editors. Ceramic Microstructure: Control at the Atomic Level. New York: Plenum Press, 1998. p. 177.

40. Shinozaki, S., Williams, R.M., Juterbock, B.N., Donlon, T., Hangas, J. and Peters, C.R., Am. Ceram. Soc. Bull., 1985, 64, 1389. 
41. Pezoldt, J., Mater. Sci. Eng., 1995, B29, 99.

42. Heuer, A.H., Fryburg, G.A., Ogbuji, L.U., Mitchell,, T.E. and Shinozaki, S., J. Am. Ceram. Soc., 1978, 61, 406.

43. Mitchell, T.E., Ogbuji,, L.U. and Heuer, A.H., J. Am. Ceram. Soc., 1978, 61, 412.

44. Ogbuji, L.U., Mitchell, T.E. and Heuer, A.H., J. Am. Ceram. Soc., 1981), 64, 90.

45. Ogbuji, L.U., Mitchell, T.E., Heuer, A.H. and Shinozaki, S., J. Am. Ceram. Soc., 1981, 64, 100.

46. van Rijswijk, W. and Shanefield, D.J., J. Am. Ceram. Soc., 1990, 73, 148.

47. Prochazka, S. and Scanlan, R.M., J. Am. Ceram. Soc., 1975, 58, 72.

48. Friederich, K.M. and Coble, R.L., J. Am. Ceram. Soc., 1983, 66, C-141.

49. Hojo, J., Miyachi, K., Okabe, Y. and Kato, A., Commun.. Am. Ceram. Soc., 1983, 66, C-114.

50. Clegg, W.J., J. Am. Ceram. Soc., 2000, 83, 39.

51. Grande, T., Sommerset, H., Hagen, E., Wiik, K. and Einarsrud, M.-A., J. Am. Ceram. Soc., 1997, 80, 1047. 